\title{
The Relationship between Work Burnout and Employees' Mental Health as Measured by GHQ-28: A Field Study Using a Sample of University Lecturers
}

\author{
Fares Jaber ${ }^{1} \&$ Marwan Al-Zoubi ${ }^{1}$ \\ ${ }^{1}$ Department of Psychology, Jordan University, Jordan \\ Correspondence: Marwan Al-Zoubi, Department of Psychology, Jordan University, Jordan. Tel: 962-6-5355-000. \\ ext. 24973. E-mail: m.al-zoubi@ju.edu.jo
}

Received: August 16, 2012 Accepted: November 6, 2012 Online Published: November 21, 2012

doi:10.5539/ijbm.v7n24p44 URL: http://dx.doi.org/10.5539/ijbm.v7n24p44

\begin{abstract}
The purpose of this study is to investigate the relationship between work burnout and employees' mental health. Burnout has been defined as the suffering of employees from exhaustion (physical energy), and disengagement (emotional energy) necessary to perform work tasks.

The sample consisted of 269 university lecturers. The sample filled two questionnaires. The first one is an Arabic version of The Olenberg Burnout Inventory (OLBI) and the second one is the General Health Questionnaire GHQ-28. Descriptive and advanced statistics such as zero order correlations and linear regression employed to analyse the data obtained from the participants in the study.

The statistical analysis revealed a significant correlation exists between burnout and mental health $(\mathrm{t}=24.25, \infty \leq$ 0.01 ). Furthermore, the results of linear regression indicated that mental health (in comparison with work load, rank, gender and age) is the strongest predictor of burnout. Some practical and theoretical implications were discussed.
\end{abstract}

Keywords: work burnout, employee mental health, academic stress

\section{Introduction}

The work burnout concept has attracted a lot of attention since its introduction in the middle of the 1970s of the last century. It has been used mostly to study employees at organizations that offer "human services" such as school teachers, health care providers, and social workers, etc. (Borritz, 2006; Maslach \& Schaufeli, 1993). Work burnout has been described as a state where the individual employee suffers from gradual depletion of the emotional and physical energy needed to perform job tasks and achieve job targets (Schaufeli and Enzmann, 1998). However, the employer expects the individual employee to be always energetic and motivated enough to achieve the work goals.

Although there are a lot of organizational factors that may contribute to work burnout, there are also some individual factors (i.e. demographical or psychological factors) that increase the person's liability to suffer form work stress (see Kompier \& Taris, 2005) and detachment from work and burnout (Demiroti et al, 2001). For example, it has been suggested that employees with maladjustment, anxity or depression may have more feelings of detachment from work, low motivation, and poor performance (e.g. Ahola, 2007; Zhong, et al. 2009). Therefore, the current study is providing a shed light on some of the individual factors that may contribute to the burnout phenomena. In particular, the main aim of this study is to examine the relationship between work burnout and employees' mental health using a sample of university lecturers.

\section{Work Burnout and Employees' Mental Health}

Many researchers have looked at burnout at work as a consequence of continuous organizational stress (Schaufeli \& Buunk, 2003; Maslach \& Schaufeli, 1993). Organizational stressors produce a state associated with several characteristics such as low self esteem, inappropriate judgement and lack of motivation and commitment (Kompier \& Taris, 2005). The individual feels that $\mathrm{s} /$ he is overwhelmed, along with bad concentration, irritable behaviour and irrational thoughts, and many mistakes on the job. Feelings of physical fatigue and negative self criticism are common among those who suffer from stressors that produce severe stress. 
Work burnout has been found to affect health. It has been found that burnout is related to fatigue and coronary vascular disease risk factors and depression (Burke \& Richardson, 1996; Melamed et al 1992; Appels \& Schouten, 1991). However, employees with such feelings may easily show anger and inflexible thinking, abuse substances, and become less productive, and committing more mistakes on the job. This state of body and mind depends on a continuous flow of unclear instructions and requirements with fatal consequences as a result of failure to perform and achieve while management is not helping the individual employee or is not allowing $\mathrm{him} /$ her to be responsible or in control of her/his actions (Karasek \& Theorell, 1990).

It can be said that work burnout is a psychological response to constant stress on the job. This response could include three elements: exhaustion, cynicism and inefficacy (Demrouti et al, 2001; Borritz, 2006). But the factors correlated with burnout are very diverse. Those factors may entail large workloads, lack of control, few rewards, lack of community, lack of fairness, clash of values, and lack of match between persons and their jobs and several background variables such as age, experience, and gender (Tsigilis, et al., 2006; Boyd \& Schnieder, 1997; Bunk \& Schaufeli, 1993). Since those who studied burnout looked at it as a result of the way employees perceive, judge and respond to stressors, which are the main source of burnout at work, one can suggest that the state of burnout interacts with mental health including attention, perception and judgment.

Literature has suggested that job burnout may have major effects on the mental health status. Ahola (2007) reviewed 27 studies conducted in USA and other western countries and concluded that job burnout has major effects on depression, anxiety and alcoholism. He noted that employees developed symptoms of depression and anxiety after starting work that need social interaction (e.g. teaching). This may indicate that bad mental health is a consequence of burnout not an anticident.

It has been found that teachers in general, whether at pre-university or at university level, often suffer from burnout. Maslach et al. (2001) reported that teachers had the highest level of emotional exhaustion of all human services jobs, whereas they achieved average scores on the other two aspects of burnout syndrome. These findings have been supported by other researchers, who have shown that the main aspect of burnout among those in teaching professions is emotional exhaustion (Koeske \& Koeske, 1989; Roohland et al., 2004; Sherirom \& Ezrachi, 2003). The emotional exhaustion aspect of burnout has been found to be a predictor of the other two aspects, i.e. depersonalization and diminished personal accomplishment (Lee \& Ashforth, 1993). Emotional exhaustion has been considered the central part of burnout (Stremmel, 1993).

Burned out teachers in general are found unable to cope properly with emotional stress (Brouwers \& Tomic, 2000). The consequences of such failure to cope can be seen in various aspects of the teaching process, mainly in bad teaching, absenteeism, and personal problems (Manlove, 1993), in another word, deterioration of the quality of education (Hogan et al. 2007; Fenech, 2006; Maslach \& leiter, 1999; Stremmel, 1993). However, the consequences of burnout may go as far as causing employees to develop depression symptoms and poor physical health (Zhong, et al. 2009). A unique PhD study concentrated on studying the causes of burnout among academics in USA found that academics feel unmotivated, cynical and burdened with many issues. They complain of lack of time, unmotivated students, bureaucratic regulations, unclear institutional expectations, and low salary (Crosmer, 2010).

The research on burnout among teaching professions showed that there are some individual factors that may increase the feelings of emotional exhaustion. Some research showed that gender has been found to interact in a significant manner with burnout in university teaching. Women generally experience higher levels of stress in their jobs and they may cope better with work demands (Doyle \& Hind, 1998). Lackritz (2004) found that female faculty members had significantly higher mean scores on emotional exhaustion than males, while male faculty had higher mean scores on depersonalization. Other studies also found that gender was an important predictor of a lower level depersonalization, and of extrinsic satisfaction in lower personal accomplishment. Additionally, it was found that the rank of the academics is capable of predicting not only emotional exhaustion but also personal accomplishment (Bilge, 2006; Dinham \& Scott 2000; Koustelios, 2001; Oshagbeemi, 1999).

Based on the above, the current study has two purposes, the first purpose is to study the relationship between work burnout and employees' mental health (as measured by general health questionnaire GHQ-28). The second purpose is to determine the ability of general mental health, and some demographic and background variables (i.e. gender, age, experience, rank, workload) in predicting the level of work burnout.

\section{Method}

To investigate the relationship between burnout and study variables on university lecturers, the following research method was employed in the study. 


\subsection{Sample}

The sample consisted of 269 Jordanian university lecturers working in one of the major public universities in Jordan. $75.5 \%$ of the total sample were males and $24.5 \%$ were females. The average age was 49.9 years $(\mathrm{SD}=$ 12). Participants had an experience of 14.4 years $(\mathrm{SD}=11.4) .40 .2 \%$ of the sample were working in the scientific colleges and the rest in the social and humanities colleges. Of the 269 responses, $46.6 \%$ were assistant professors, $16 \%$ were associate professors, and the rest were full professors. Finally, the average work load for the semester in which data was collected ranged between 3-18 credit hours with an average of 12.1 hours (SD= 3.9). Table (1) shows a breakdown of respondents by age, gender, experience, work load and rank.

\subsection{Tools}

\subsubsection{Work Burnout}

The work burnout was measured by job related burnout scale. This scale was developed by Demrouti and Nachreiner (see Demrouti et al, 2001) on a sample of German employees from different occupational fields. This scale measures burnout on two dimensions: exhaustion and disengagement. The items of the exhaustion subscale refer to general feelings of emptiness, overtaxing from work, a strong need for rest, and a state of physical exhaustion. Example items are "after my work, I usually feel worn and weary", and "after my work I feel totally fit for my leisure activities" (reversed). Three items are positively worded and four, negatively. Disengagement refers to distancing oneself from the object and the content of one's work and to negative, cynical attitudes and behaviors towards one's work in general. Example items are "I usually talk about my work in a derogatory way" and "I get more and more engaged in my work" (reversed). Responses were indicated on a 4-point Likert style scale as follows: $(1=$ totally disagree, $2=$ disagree, $3=$ agree, $4=$ totally agree $)$. The total score of all items presents the level of burnout, with a higher score indicating greater burnout.

Demrouti et al (2001) indicated that the scale has acceptable levels of validity and reliability. As to the validity, a factor analysis confirmed its two-dimensional factor structure. Discriminate and convergent validity was examined by relating the scale to items from a scale developed by other researchers to measure job-related strain. The correlation was high, which provides support to the structure of the scale. As to reliability, the authors indicated that the scale has acceptable internal consistency coefficients using the Chronpach Alpha formula (alpha $=0.83$ ) (see Demrouti et al, 2001).

An Arabic translation of the scale was produced by the researchers from the English version of the scale. Back translation was provided by English language professionals. Based on the notes provided, some minor amendments were made. The scale was tested on a small sample of employees to ensure that there were no misleading or ambiguous items. The scale achieved acceptable internal consistency on the present sample (alpha $=0.84$, which is close to the reliability of the English version of the scale).

\subsubsection{General Mental Health}

This variable was measured by the General Health Questionnaire-28 (Goldberg, 1978). GHQ-28 is a 28 -item measure of emotional distress that is divided into 4 subscales: somatic symptoms (e.g. run down), anxiety/insomnia (e.g. lost sleep over worry), social dysfunction (e.g. taking longer over things), and severe depression (e.g. life not worth living). The total score of the scale can be used as a measure of psychological distress, with a higher score indicating greater distress and therefore lower mental health. The GHQ- 28 has been used extensively in previous research.

High internal consistency has been reported with range from 0.82 to 0.93 (Goldberg \& Williames, 1988). The scale has a Jordanian version in Arabic. The validity and reliability coefficients of the Arabic version were acceptable. The internal consistency on the current sample was $($ alpha $=0.83)$ which indicates that the scale has acceptable reliability.

Responses were indicated by participants using the scale's simple Likert-type method. In this scale, respondents indicate if their current "state" differs from their usual state, thereby assessing change in characteristics and not lifelong personality characteristics.

\subsubsection{Work Load and Demographics}

All participants were asked to provide information about their gender, age, experience and academic rank. In addition, individuals were asked to indicate their teaching workload (i.e. number of credit hours they teach) in the semester when they filled in the questionnaire.

\subsection{Procedures}

Academics were encouraged by a letter from the president of the university to fill in the questionnaire and 
participate in this study. University professors were approached and asked by trained research assistants to fill in a questionnaire. 269 lecturers agreed to participate and filled in the questionnaires in full.

\subsection{Statistical Methods}

To achieve study aims, two steps of analysis were performed. First, descriptive statistics were computed to examine the overall burnout levels and general psychological health according to different demographic variables of the university lecturers. The second step was computation of advanced statistics in which the effects of general mental health, age, gender, workload, tenure, academic rank on burnout were investigated using zero order correlations and linear regression. All missing data were deleted listwise. Therefore, the number of respondents may vary according to the variable used in classification.

\section{Results}

This study had two aims, the first aim is study the relationship between work burnout and employees' mental health (as measured by general health questionnaire GHQ-28). The second aim was to determine the ability of general mental health, and some demographic and background variables (gender, age, experience, rank, workload) in predicting the level of work burnout.

To achieve the aims of this study, descriptive statistics, zero order correlations and liner regressions were used. Table (1) presents the overall burnout levels and general mental health across the different classifications of university lecturers (i.e. gender, age, tenure, and academic rank).

Table 1. Overall burnout levels and general mental health across gender, age, experience, and academic rank of academics

\begin{tabular}{clccccc}
\hline \multirow{2}{*}{ Variables } & \multirow{2}{*}{ Variable sub- levels } & Sample & \multicolumn{2}{c}{ Burnout* } & \multicolumn{2}{c}{ General mental health ** } \\
\cline { 4 - 6 } & & percentage & $\mathrm{M}$ & $\mathrm{SD}$ & $\mathrm{M}$ & $\mathrm{SD}$ \\
\hline \multirow{3}{*}{ Age } & Less than 35 years & $26.6 \%$ & 38.7 & 6.4 & 56.6 & 8.3 \\
& 36- 50 years & $43.1 \%$ & 34.9 & 5.4 & 54.4 & 7.6 \\
& 51-70 years & $30.3 \%$ & 31.8 & 6.1 & 51.9 & 5.9 \\
Gender & Male & $75.8 \%$ & 34.2 & 6.1 & 53.5 & 6.9 \\
& Female & $24.2 \%$ & 37.2 & 7.2 & 56.2 & 8.6 \\
& Less than 5 years & $30.8 \%$ & 37.9 & 5.9 & 54.9 & 8.1 \\
Experience & 6- 10 years & $18.5 \%$ & 34.6 & 5.83 & 55.9 & 7.4 \\
& More than 10 years & $50.7 \%$ & 33.4 & 6.16 & 53.4 & 7.1 \\
Academic & Assistant Prof & $50.7 \%$ & 36.9 & 6.4 & 54.8 & 7.3 \\
rank & Associate Prof & $18.1 \%$ & 34.2 & 5.2 & 54.4 & 7.6 \\
& Full Prof & $31.2 \%$ & 31.9 & 6.9 & 53.1 & 8.1 \\
Teaching & 6 credit hours or less & $10.9 \%$ & 32.8 & 3.79 & 51.8 & 6.4 \\
Workload & 7-12 credit hours & $53.5 \%$ & 34.1 & 6.9 & 53.5 & 6.5 \\
& More than 12 credit hours & $35.6 \%$ & 36.7 & 5.8 & 55.2 & 7.6 \\
\hline
\end{tabular}

* High score means higher burnout level

** High score means higher distress level and therefore lower general mental health

Table (1) indicates that there were differences in the means of burnout and mental health according to gender, age, tenure, academic rank and teaching workload. As for age, Table (1) indicates that the highest burnout was for professors aged less than $35(\mathrm{M}=38.7, \mathrm{SD}=6.4)$ while the lowest burnout mean was for professors aged between 51 and 70 years $(\mathrm{M}=31.8, \mathrm{SD}=6.1)$. In general, burnout decrease as age increases. The same findings also apply for the mental health means, in which younger professors have more distress and therefore, less mental health than older ones.

Furthermore, there were mean differences according to gender. In general, females have higher burnout means and lower mental health than males. The burnout mean for males was $(34.2, \mathrm{SD}=6.1)$ while that for females (37.2, $\mathrm{SD}=7.2)$. The mean for distress among females was $(56.2, \mathrm{SD}=8.6)$ which was higher than among males 
$(\mathrm{M}=53.5, \mathrm{SD}=6.9)$. In addition, there were differences in burnout and distress means based on tenure. Professors who have only five years or less of working experience in the university have the highest burnout mean $(\mathrm{M}=35.9, \mathrm{SD}=5.9)$. However, this does not apply to the mental health, as the differences in distress means according to experience was not large and the highest mean in distress were among employees with medium experience $(\mathrm{M}=51.9, \mathrm{SD}=7.4)$.

There were also differences in burnout means and distress levels based on academic rank. Full professors had the lowest burnout mean $(\mathrm{M}=31.9, \mathrm{SD}=6.9)$ and the lowest distress level $(\mathrm{M}=53.1, \mathrm{SD}=8.1)$, indicating better mental health. Finally, according to teaching workload, the results indicate that academics with a work load of more than 12 credit hours per semester have the highest burnout mean $(\mathrm{M}=36.7, \mathrm{SD}=5.8)$ and the highest distress mean $(\mathrm{M}=55.1, \mathrm{SD}=7.6)$, while academics who have a work load of 6 credit hours or less have the lowest burnout means $(\mathrm{M}=33, \mathrm{SD}=7.8)$ and better mental health, i.e. low distress $(\mathrm{M}=51.8, \mathrm{SD}=6.4)$.

To answer the first question in this study, a zero order correlations for study variables was produced. The aim was to explore the nature of relationships between all variables. Table (2) presents the zero order correlations between study variables.

Table 2. Zero order correlations between study variables

\begin{tabular}{llllllll}
\hline & Burnout & Mental health & Gender & Age & Experience & Work Load & Rank \\
\hline Burnout & 1 & & & & & & \\
Mental health & $.549^{* *}$ & 1 & & & & & \\
Gender & $.162^{*}$ & $.178^{*}$ & 1 & & & & \\
Age & $-.407^{* *}$ & $-.190^{*}$ & $-.402^{* *}$ & 1 & & & \\
Experience & $-.389^{* *}$ & $-.178^{*}$ & $.689^{* *}$ & $-.219^{* *}$ & 1 & & \\
Work Load & $.284^{* *}$ & .16 & $.681^{* *}$ & $-.238^{* *}$ & $.848^{* *}$ & 1 & \\
Rank & $-.331^{* *}$ & -.101 & $-.356^{* *}$ & .098 & $-.173^{*}$ & $-.269^{* *}$ & 1 \\
$* * \mathrm{P} \leq 0.01, * \mathrm{P} \leq 0.05$ & & & & & & & \\
\hline
\end{tabular}

Table 2 indicates that the highest correlation between study variables and burnout was for general mental health $(\mathrm{R}=0.549, \infty \leq 0.01)$, then for age $(\mathrm{R}=-0.407, \infty \leq 0.01)$, followed by experience $(\mathrm{R}=-0.389, \infty \leq 0.01)$, workload $(\mathrm{R}=0.284, \infty \leq 0.01)$ and finally gender $(\mathrm{R}=0.202, \infty \leq 0.01)$. In general, all studied variables have significant correlations with burnout. However, gender, workload, and mental health (i.e. distress level) have positive correlations, while age, tenure, and rank have negative correlations with burnout level.

The next step in the analysis was determining the ability of general mental health, gender, age, experience, academic rank in predicting the level of burnout among academics. Table (3) presents the results of the linear regression analysis in which gender, age, experience, teaching load, academic rank, and mental health were entered individually as independent variables and burnout as the dependent variable.

Table 3. The results of linear regression between study variables and burnout

\begin{tabular}{lccc}
\hline Regressions & $\mathrm{B}$ & $\mathrm{T}$ & $\mathrm{R}^{2}{ }_{\Delta}$ \\
\hline General mental health and Burnout & .549 & $7.66^{*}$ & 0.29 \\
Gender and Burnout & .202 & $2.49^{*}$ & 0.03 \\
Age and Burnout & -.407 & $-5.39^{*}$ & 0.16 \\
Experience and Burnout & -.389 & $-5.12^{*}$ & 0.14 \\
Academic rank and Burnout & -.331 & $-4.09^{*}$ & 0.10 \\
work load and Burnout & .440 & $3.56^{*}$ & 0.07 \\
\hline
\end{tabular}

* $\mathrm{P} \leq 0.01, \mathrm{R}_{\Delta}^{2}=$ adjusted $\mathrm{R}$ square, $\beta=$ beta value

Table (3) indicates that the variable that has the highest predictability factor was the general mental health which predicted $29 \%$ of the total variance $\left(\mathrm{R}_{\Delta}^{2}=0.29, \infty \leq 0.01\right)$. The second variable was age, which predicted $16 \%$ of 
the total variance $\left(\mathrm{R}_{\Delta}{ }_{\Delta}=0.16, \infty \leq 0.01\right)$. Experience and rank took the third and fourth places predicting $14 \%$ and $10 \%$ of the total variance $\left(\mathrm{R}_{\Delta}^{2}=0.14,0.10, \infty \leq 0.01\right)$ respectively. Finally, gender and workload do not have predictability indices in comparison with the rest of variables ( $3 \%$ and $7 \%$ respectively).

\section{Discussion}

This study provided an outline of the structure of the burnout state and its relation to employees' mental health as measured by the GHQ-28 using a sample of university lecturers. The results presented in table 2 indicated clearly that mental health state and burnout has significant correlation. This means that mental health state may affects the person's perception, thinking and judgment of their situation and other factors that affect his or her life. This is inline with the research conducted in the occupational health field (see Kompier \& Taris, 2005). Therefore, its influence on the state of burnout is expected as we can see in table $2 \& 3$. Furthermore, mental health predicted work burnout more than other employee demographics such as age and gender. This provides strong indication to the importance of the role of mental health in coping with work stress and burnout. These results are aligned with other studies conducted in this field (e.g. Crosmer, 2010; Hogan \& Mcknight, 2007; Lackritz, 2004).

The above result has major implications on employee life and performance. If the individual employee cannot evaluate and handle stressors successfully, then burnout will start to take place and develop further. Intensive and continuous burnout may affect mental health in general and may lead to develop depression and anxiety. Such psychological disorders will affect employee motivation, commitment, absence and performance in general (Ahola, 2007; Zhong et al, 2009; Tsigilis, et al., 2006; Lerman, 1999).

It has been suggested that mental health does not mean just the absence of mental illness. It also means a state of general health or psychological well-being where the individual can function successfully in society. In other words, psychologists in general, and health psychologists in particular, believe that those who enjoy a better level of normal psychological health will be able to respond effectively to life and job demands in a way that will satisfy their needs and those of society at the same time (Barling. et al 2004, Warr, 1994, O'Driscoll, 2002).

Additionally, the statistical analysis of the data presented in tables 1, 2, and 3 shows that factors of mental health, age, experience, work load, and gender do interact with the burnout state of the lecturers in a significant manner. These findings are inline with the previously reported research results conducted in other work places or professionals in other occupations (Zhong et al, 2009; Rohland et al., 2004; Sherirom \& Ezrachi, 2003). It also seems that these results lend support to the validity of the concepts and tools used in these studies.

Burnout and decreasing commitment have been regarded as major problems in jobs that deal with people (Maslach C, \& Schaufeli, 1993). The variables examined in this study address these issues, and furthermore, points out two options to foster professors' well-being, health, and mental health. The results here suggest that efforts aiming at the reduction of work load and the prevention of burnout should be of primary concern for people working in the teaching organizations. The other important and parallel route consists of activities to increase job resources which potentially lead to higher levels of work engagement, lower levels of burnout, and stronger mental health. Additionally, according to Demourit's (2001) model, disengagement from work is a consequence of getting less rewards. Therefore, more rewards should be awarded to the lecturers in the assistant professor rank.

In general, it can be said that justice, fairness, and autonomy in the work place most probably will increase morale, human relations, motivation, commitment, well being, engagement, and happiness. Such positive and good feelings most probably will reduce work burnout and therefore, may reduce the likability of developing psychological and behavioral disorders. Such work environment may reflect in work output in quantity and quality.

Finally, we should note that the current study has some limitations that should be mentioned. Most importantly, the findings come from a study of cross-sectional design. Therefore, although we have claimed to study processes in teachers' well-being, it is not possible to draw final conclusions about the causal relationships between the study variables. Longitudinal study designs are needed to examine the proposed processes. A second limitation is that all the data were based on self-reports. Objective indicators of health status and commitment to the job and the organization should be employed to rule out the potential effects of common method variance. Observer ratings have been successfully used to study working conditions and their relationships with burnout (Demerouti et al., 2001). It would therefore be interesting for future studies to expand on the present study by testing the relationships between objective demands and resources on the one hand, and work engagement on the other. 


\section{References}

Ahola, K. (2007). Occupational burnout and health. Finish Institute of Occupational Health. Report 81. Helsinki.

Appels, A., \& Schouten, M. (1991). Burnout as a risk factor for coronary heart disease. Behavior Med., 17, 9-53. http://dx.doi.org/10.1080/08964289.1991.9935158

Barling, J. (2004). The Handbook of Work Stress. California: Sage.

Bilge, F. (2006). Examining the Burnout of Academics in Relation to Satisfaction and other Factors. Social Behaviour and Personality: An International Journal, 9, 1151-1160. http://dx.doi.org/10.2224/sbp.2006.34.9.1151

Borritz, M. (2006). Burnout in Human Service Work, causes and consequences. Unpublished PhD Thesis. National Institute of Occupational Health, Denmark.

Boyd, B., \& Schneider, N. (1997). Perceptions of the work environment and burnout in Canadian child care providers. Childhood Education, 11(2), 171-180. http://dx.doi.org/10.1080/02568549709594704

Brouwers, A., \& Tomic, W. (2000). A longitudinal study of teacher burnout and perceived self efficacy in classroom management. Teaching and Teacher Education, 16, 239-253. http://dx.doi.org/10.1016/S0742-051X(99)00057-8

Bunk, B., \& Schaufeli, W. (1993). Burnout: a perspective from social comparison theory. In Schaufeli W., Maslach C., \& Marek T. (eds.), Professional Burnout: Recent Developments in Theory and Research. New York: Taylor \& Francis.

Burke, R., \& Richardson A. (1996). Stress, burnout and health. In Cooper CL. (ed.), Handbook of stress, medicine and health. CRC Press.

Crosmer J. (2010). The causes of burnout and disillusionment among academics. Unpublished $\mathrm{PhD}$ theses. Texas Women University. Texas, USA.

Demerouti, E., Bakker, A., Nachreiner, F., \& Schaufeli, W. (2001). Job Demands-Resources Model of burnout. Journal of Applied Psychology, 86, 499-512. http://dx.doi.org/10.1037/0021-9010.86.3.499

Dinham, S., \& Scott, C. (2000). Moving into the third outer domain of teacher satisfaction. Journal of Educational Administration, 38(4), 379-396. http://dx.doi.org/10.1108/09578230010373633

Doyle, C., \& Hind, P. (1998). Occupational stress Burnout and job status in female Academics. Gender, Work \& organization, 5(2), 67-82. http://dx.doi.org/10.1111/1468-0432.00047

Fenech, M. (2006). The Impact of Regulatory Environments on Early Childhood Professional Practice and Job Satisfaction: A review of conflicting discourses. Australian Journal of Early Childhood, 31(2), 49-57.

Goldberg D. (1978). Manual of the General Health Questionnaire. Windsor: NFER-Nelson.

Goldberg, D., \& Williams, P. (1988). A User's Guide to the General Health Questionnaire. NFER-Nelson: Windsor.

Hogan, R., \& Mcknight, M. (2007). Exploring burnout among university online instructors. Internet \& Higher education, 10(2), 117-124. http://dx.doi.org/10.1016/j.iheduc.2007.03.001

Karasek, R., \& Theorell, T. (1990). Healthy Work: Stress, productivity, and the reconstruction of working life. Basic Books, New York.

Koeske, R., \& Koeske G. (1989). Working and Non Working Students: Roles, Support and Well Being. Journal of Social Work Education, 25, 244-56.

Kompier, M., \& Taris T. (2005). Psychosocial risk factors and work-related stress: state of the art and issues for future research. In Antonio, A. \& Cooper, C. (eds.), Research companion to organizational health psychology. Edward Elgar Publishing Limited, UK.

Koustelios A. (2001). Personal characteristics and job satisfaction of Greek teachers. The International Journal Education Manager, 15(7), 354-358. http://dx.doi.org/10.1108/EUM0000000005931

Lackritz, D. (2004). Exploring burnout among university faculty: Incidence, performance, and demographic issues. Teaching and Teacher Education, 20, 713-729. http://dx.doi.org/10.1016/j.tate.2004.07.002

Lee, R., \& Ashforth, B. (1993). A longitudinal study of burnout among supervisors and managers: Comparisons between the Leiter and Maslach (1988) and Golembiewski et al. (1986) models. Organizational Behavior 
and Human Decision Processes, 54, 369-398. http://dx.doi.org/10.1006/obhd.1993.1016

Manlove, E. (1993) Multiple correlates of burnout in child care workers. Early Childhood Res. Q., 8(4), 499-518. http://dx.doi.org/10.1016/S0885-2006(05)80082-1

Maslach C., \& Leiter, M. (1999). Teacher burnout: A Research Agenda. In Vandenberghe R., \& Huberman A. (eds.), Understanding and Preventing teacher burnout. Cambridge, UK: Cambridge University Press. http://dx.doi.org/10.1017/CBO9780511527784.021

Maslach C., \& Schaufeli, (1993). Burnout: A Multidimensional Perspective. In Schaufeli WB, Maslach CH, Marek T. (eds.), Professional Burnout: Recent Developments in Theory and Research. NY: Taylor \& Francis.

Maslach, C., Schaufeli W., \& Leiter, P. (2001). Job burnout. Ann Review Psychology, 52, 397-422. http://dx.doi.org/10.1146/annurev.psych.52.1.397

Melamed S., Kushnir T., \& Shirom, A. (1992). Burnout and Risk factors for cardiovascular diseases. Behaviour Medicine, 18, 53-60. http://dx.doi.org/10.1080/08964289.1992.9935172

O'Driscoll, M. (2002). Job related stress and burnout. In Warr, P (ed.), Psychology at work (5th ed.). Penguin Books. England.

Oshagbemi, T. (1999). Academics and their managers: a comparative study in job satisfaction. Personnel Review, 28(1/2), 108-123. http://dx.doi.org/10.1108/00483489910249027

Rohland B., Kruse G., \& Rohrer J. (2004). Validation of a single-item measure of burnout against the Maslach Burnout Inventory among physicians. Stress \& Health, 20(2), 75-79. http://dx.doi.org/10.1002/smi.1002

Schaufeli W., \& Buunk B. (2003). Burnout: An Overview of 25 Years of Research and Theorizing. In Schabracq MJ, et al (eds.), The Handbook of Work and Health Psychology (2nd ed.). West Sussex, England: Wiley.

Schaufeli W., \& Enzmann D. (1998). The Burnout companion to study and practice: a critical analysis. London: Taylor \& Francis.

Shirom A., \& Ezrachi, Y. (2003). On the discriminant validity of burnout, depression and anxiety: A re-examination of the burnout measure. Anxiety, Stress and Coping, 16(1), 83-97. http://dx.doi.org/10.1080/1061580021000057059

Stremmel, A. (1993). Communication, satisfaction, and emotional exhaustion among child care centre staff. Early Childhood Research Quarterly, 8(2), 221-233. http://dx.doi.org/10.1016/S0885-2006(05)80092-4

Tsigilis, N., Zachopoulou, E., \& Grammatikopoulos, V. (2006). Job satisfaction and burnout among Greek early childhood educators: a comparison between public and private sector employees. Educational Research and Review, 1, 256-261.

Warr, P. (1994). A conceptual framework for the study of work and mental health. Work and stress, 8, 84-97. http://dx.doi.org/10.1080/02678379408259982

Zhong J., Jianing Y., Yiqun G., Ytwen Z., Changqin L., \& Hongbo W. (2009). Job stress, burnout, depression symptoms, and physical health among Chinese university teachers. Psychological Reports, 105(3), 1248-1254. http://dx.doi.org/10.2466/pr0.105.F.1248-1254 